\title{
Childlessness in Europe: Contexts, Causes, and Consequences
}

\author{
edited by Michaela Kreyenfeld and Dirk Konietzka \\ Dordrecht: Springer, 2017 \\ Demographic Research Monograph Series \\ ISBN 978-3-319-44665-3 \\ Hardcover US\$59.99, 381 pp.
}

Partially translated from Ein Leben obne Kinder (Springer 2013)

\section{Reviewed by Vita Yakovlyeva \\ University of Alberta}

This impressive, statistic-dense volume, published by the Max Planck Institute for Demographic Research, presents an overview of trends in demographic behaviour toward childlessness, focusing primarily, though not exclusively, on Western Europe. The main conceptual issues under consideration in this volume are: (1) the determinants of the growth of childlessness over time; and (2) the possibility of its reversal. While the individual chapters take on a range of topics, the most prevalent of these are inquiries into the social stratification of childlessness as well as the social and biological limits of childlessness, including fertility, the family, and their relationship to social policy. Germany, Sweden, and Finland receive special attention; however, given the availability of longitudinal studies, the authors successfully extend their inquiry into the data sets available from elsewhere in Central, Eastern, and Southeastern Europe-the UK, Scandinavia, Italy, Austria, Slovenia, Czech Republic, etc. (and even the US). The timespan covered by the research presented stretches from the 1880s to approximately 2012.

Childlessness makes several crucial and commendable contributions to the discipline of demography, and to social studies of population in general, such as family, children, or ageing studies. Although levels of childlessness in most European countries have been observed to rise in recent decades, childlessness is not a new phenomenon. The publication meticulously traces the continuity of childlessness hundreds of years back in time, and seeks to ground its varied analyses in the historical context of the phenomenon while taking into consideration the many variables that might influence the general demographic trends of population, such as migration, poverty, war, religious affiliation, gender, etc. (chapter 2).

A key finding of the book is that the childless population is a very heterogeneous group. Among the important novel discoveries is, for instance, a link between childlessness and sibling socialization. Some recent evidence suggests that a decline in the number of children can become generational and is associated with increased childlessness in the future for individuals who grew up in small families. Generally, there are many variables that have never been properly articulated, and this publication successfully pins some of them down, such as religious affiliation, migration, and the practice of foster or social parenting. As such, the works collected in this volume emphasize the complexity of the phenomenon under study. For example, several contributions to this 
volume trace differences in both male and female childlessness by educational attainment. It has been repeatedly suggested that high levels of childlessness are associated with progressive growth of tertiary education among women, and frequently this has been simplistically linked to emancipation. However, recent examples of statistics from Finland and other Nordic countries presented in this book demonstrate a reversal in this trend: in the last decades, childlessness levels in Finland have become highest among the least-educated men and women (chapter 7).

Taken together, the studies presented in the volume debunk a direct causal pathway linking childlessness to lower education among men and higher education among women, while pointing out other variables whose weight has previously been underestimated, such as cognitive abilities, state family policy, or lack of a partner. By refusing to attribute childlessness to a single clear-cut reason, the book promotes attention to the complexity of individual reproductive choice. For example, the contributions that demonstrate most successfully the correlation between social circumstances and individual fertility decisions are represented by the studies comparing East and West Germany (chapter 5), Austria and Switzerland (chapter 6), and Austria and Sweden (chapter 9). Tracing differences in the fertility trends in East and West Germany before and after unification demonstrates how "radical changes on the macro level transfer into cohort-specific behavioral patterns" (p. 102). Chapters 5, 6, and 9 successfully present a comprehensive framework of socioe-conomic factors to explain the hypothesis that institutional infrastructure that provides substantial support for the integration of mothers into the full-time labour market is one of the leading factors to influence childlessness in educated women. Instead of merely analyzing the family policy in a given country, the authors underline the importance of taking a life course approach to understanding the role of institutions in shaping childbearing decisions.

Despite the rich data collection and sound analysis in Childlessness, some minor drawbacks that are common to the majority of works in this volume deserve mention. Any reader equipped in social theory will notice that social theory as such is gestured towards but not at all sufficiently explored across the volume, even in those articles that claim the use of a certain theoretical framework in their research of childlessness. For example, those drawing on the life course approach (e.g., chapters 9-11) briefly summarize its definition but fail to actually demonstrate the process of its application or sufficiently unpack the logic of their arguments. The authors of chapter 12 rightfully bring in Bourdieu's concept of habitus in order to trace some patterns between fertility dispositions and socialization in a given social environment, and yet they leave the reader looking for a more explicit application of this concept to the data set under study. The concept of habitus is mentioned only twice_-once in the subsection "Theoretical and Empirical Background" and then once more in the concluding subsection of the chapter, but apparently slips between the lines in the rest of the chapter.

The editorial introduction seems to share the style of the volume, which emphasizes the presentation of recent and crucially valuable, mostly quantitative data (with exception of chapter 12, which draws on interviews), but refrains from much theoretical interpretation. In addition to a lack of engagement with relevant social theory, the book presents a number of issues with regard to clarity. For instance, in the introduction the editors insist on putting the concepts of voluntary and involuntary childlessness in quotation marks, while everywhere else in the volume, and in demographic vocabulary in general, both concepts exist as valid without such an unnecessary hint at unusualness or ambiguity, as is normally conveyed by quotation marks. Furthermore, some attentive readers can be left puzzled by the possible meanings implied by another unjustified pair of quotation marks around the verb to choose, in the context of talking about reproductive choice. Such a choice of punctuation could be interpreted as a possible implication of a negative meaning ascribed to the flaw feature of the "current generations" (p. 4). In another instance of troubling ambiguity, 
after having just described a feminist perspective on the vocabulary of childlessness studies, the editors go on to contrast it with what they call "a more neutral and fact-based assessment of the consequences of childlessness" (p. 3). Such a formulation seems dismissive of the feminist approach's contribution to studies of parenthood and children, as well as suggests its inability to generate sound, scholarly evidence. Here and elsewhere, the editors do not explain their choices. Similarly, the tantalizing question that the editors pose to themselves of whether childlessness can be considered a postmodern phenomenon is left essentially unexplored and ultimately unanswered.

Overall, this is a selection of important contemporary demographic research that should attract a diverse readership of social scientists and policy makers. It sheds light on some concepts positioned right on the edge of development of some reproductive theories and practices that still await further in-depth exploration, such as the rights of the fetus conceived with Assisted Reproduction Technologies (ART) and the social implications of childlessness in seniors. 